\title{
Solutions for the "difficult-to-deform" wrought superalloys
}

\author{
Zhongnan Bi, Xudong Lv, and Ji Zhang ${ }^{\mathrm{a}}$ \\ High Temperature Materials Division, China Iron and Steel Research Institute Group, Beijing 100081, China
}

\begin{abstract}
Microstructure observation suggested that slowing down the cooling rate influence $\gamma^{\prime}$ precipitation obviously and consequently produces coarse $\gamma^{\prime}$ which could significantly improve plastic flow behavior that helps to break down the cast microstructures of wrought superalloys with high volume fraction of $\gamma^{\prime}$. After full recrystallization, a modified dual-phase microstructure containing refined $\gamma$ matrix plus coarse $\gamma^{\prime}$ shows superplasticity during subsequent hot deformation. It also proved that soft lagging casing method is effective to retard the surface heat radiation of the pre-heated ingots during cogging operation.
\end{abstract}

\section{Introduction}

To further improve the efficiency of combustion processes, the maximum operating temperature has to be elevated. Consequently, Ni-based superalloys as mostly used structural materials for turbine systems have to be more tolerated at high temperatures [1,2]. Essentially, volume fraction increment of $\gamma^{\prime}$ is effective to enhance the strength retention and creep resistance of Ni-based superalloys [3-6]. While, nevertheless increasing $\mathrm{Al}$ and $\mathrm{Ti}$ contents for more $\gamma^{\prime}$ precipitation deteriorate the hot deformability as well for wrought alloys especially during cogging process. Some alloys with higher Al and Ti contents could not be deformed at the single austenite state due to the increased solvus temperature of $\gamma^{\prime}$ (as illustrated in Fig. 1). So the predominant impact is the loss of pyroplasticity because of the precipitates' hardening effect by $\gamma^{\prime}$ during hot working. The other significant influence is that the temperature windows for hot working was shrunk since the temperatures for dynamic recrystallization to cause flow softening ascend while the incipient melting temperatures descend as the result of aggravated hot workability [7-9]. Those negative effects have been being the bottle neck in the production of wrought superalloys with higher $\mathrm{Al}$ and $\mathrm{Ti}$ contents. Therefore, this kind of superalloys is also called "Difficult-to-Deform" wrought superalloys.

This paper review the current work on improving the plastic flow behavior of wrought Ni-based superalloys with high $\mathrm{Al}$ and $\mathrm{Ti}$ contents by pre-modifying the microstructures with coarse $\gamma^{\prime}$. A soft lagging casing method was also proposed to retard the surface heat radiation of the pre-heated ingots during the operation in normal hydraulic press.

\section{Experiment procedures}

As a typical "Difficult-to-Deform" turbine disk used superalloy, 720Li alloy was selected to be the investigated

\footnotetext{
${ }^{a}$ Corresponding author: zhaji@public3.bta.net.cn
}

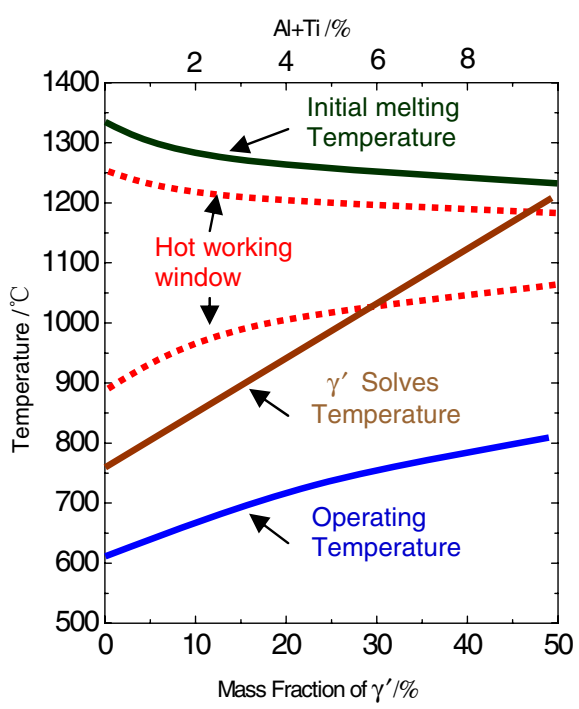

Figure 1. General characters of Ni-based superalloys with increased $\mathrm{Al}+\mathrm{Ti}$ contents.

Table 1. Chemical composition of the investigated 720Li alloy (w.t. \%).

\begin{tabular}{|l|c|c|c|c|}
\hline $\mathrm{Al}$ & $\mathrm{B}$ & $\mathrm{C}$ & $\mathrm{Co}$ & $\mathrm{Cr}$ \\
\hline 2.50 & 0.0115 & 0.016 & 14.5 & 16 \\
\hline $\mathrm{Mo}$ & $\mathrm{Si}$ & $\mathrm{Ti}$ & $\mathrm{W}$ & $\mathrm{Ni}$ \\
\hline 3.00 & 0.10 & 5.00 & 1.20 & $\mathrm{Bal}$ \\
\hline
\end{tabular}

material in this study. The chemical compositions are shown in Table 1. The mass fraction of $\mathrm{Al}$ plus $\mathrm{Ti}$ is $7.5 \%$. The volume fraction of $\gamma^{\prime}$ is $40 \sim 45 \%$ after heat treatment, and the solves temperature of $\gamma^{\prime}$ is about $1160{ }^{\circ} \mathrm{C}[2,10,11]$.

The original samples were cut from an ingot, with as cast microstructure. After homogenization treatment, it changes into large austenite grains. The grain size is larger than 1000 micro meters as shown in Fig. 2.

This is an Open Access article distributed under the terms of the Creative Commons Attribution License 4.0, which permits unrestricted use, distribution, and reproduction in any medium, provided the original work is properly cited. 


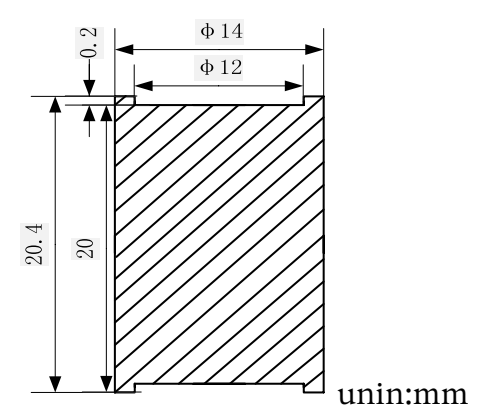

Figure 2. Sample size and deforming conditions of thermalcompression tests.

Different morphologies and sizes of $\gamma^{\prime}$ were gotten by cooling treatments form $1165^{\circ} \mathrm{C} \rightarrow 1000^{\circ} \mathrm{C}$ with various cooling rates.

Another set of samples were cut from a wrought bar, with "modified dual-phase microstructure". The grain size is about $5 \sim 10$ micro meters, with coarse $\gamma^{\prime}$ at grain boundaries.

The flow behavior and thermo-plasticity of the samples with different initial grain sizes or $\gamma^{\prime}$ morphologies were studied by isotherm-compression tests respectively using MTS machine. The sampling size is shown in Fig. 1. Glass lubricant was daubed into the grooves at end faces for homogeneous deformation.

The test conditions are as followed:

Temperature: $1070{ }^{\circ} \mathrm{C}, 1100^{\circ} \mathrm{C}, 1130{ }^{\circ} \mathrm{C}, 1160^{\circ} \mathrm{C}$, $1190^{\circ} \mathrm{C}$.

Strain rate: $0.5 \mathrm{~s}^{-1}, 0.1 \mathrm{~s}^{-1}, 0.01 \mathrm{~s}^{-1}, 0.001 \mathrm{~s}^{-1}$, $0.0001 \mathrm{~s}^{-1}$.

Strain: $10 \%, 30 \%, 50 \%, 70 \%$.

Microstructure observations by OM, SEM and TEM were also carried out to study the microstructure evolution mechanisms at different deforming conditions.

The samples were electro-polished in a solution of

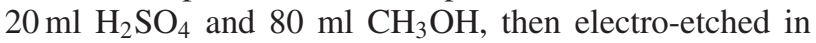
a solution of $170 \mathrm{ml} \mathrm{H}_{3} \mathrm{PO}_{4}, 10 \mathrm{ml} \mathrm{H}_{2} \mathrm{SO}_{4}$ and $15 \mathrm{~g} \mathrm{CrO}_{3}$ to reveal the microstructure.

\section{Results and discussion}

\subsection{Microstructure modification during cooling process before deformation}

The samples for microstructure modification before deformation were all cut from an ingot, with as cast microstructure. After homogenization treatment, it changes into large $\gamma$ grains with nearly no residual blocky $\gamma^{\prime}$ as shown in Fig. 3 .

It was found that the size and morphology of $\gamma^{\prime}$ are very sensitive to cooling rate during cooling process from single $\gamma$ region to $\gamma+\gamma^{\prime}$ dual-phase region. So different $\gamma^{\prime}$ precipitates were gotten by cooling treatments from $1165^{\circ} \mathrm{C} \rightarrow 1000^{\circ} \mathrm{C}$ with various cooling rates (then air cooled from $1000^{\circ} \mathrm{C}$ to room temperature).

As shown in Fig. 4, the average size and spacing of $\gamma^{\prime}$ both increase with decreased cooling rate. The shape of $\gamma^{\prime}$ precipitates is spherical or at least nearly spherical after ordinary air cooling. Lower cooling rates cause an increase in the mean particle diameter to decrease the total
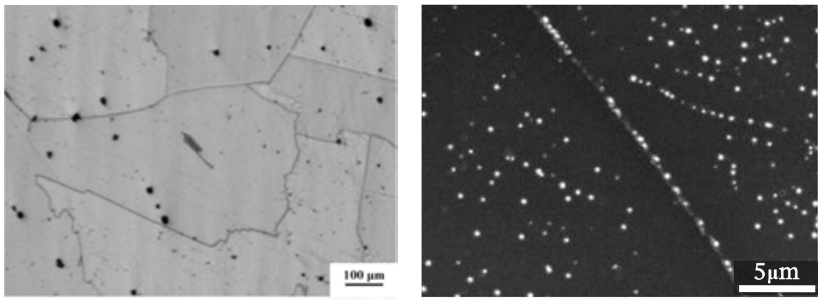

Figure 3. Initial microstructure before modification.
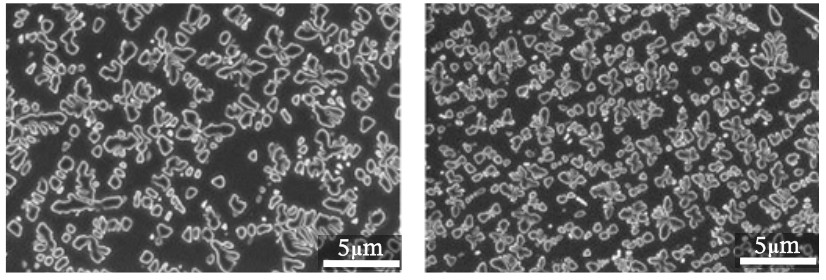

$20^{\circ} \mathrm{C} / \mathrm{h}$

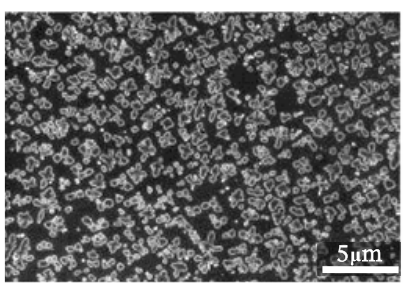

$100^{\circ} \mathrm{C} / \mathrm{h}$

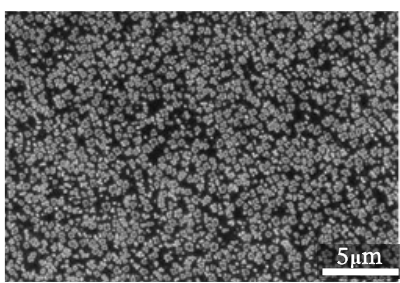

$500^{\circ} \mathrm{C} / \mathrm{h}$ $50^{\circ} \mathrm{C} / \mathrm{h}$

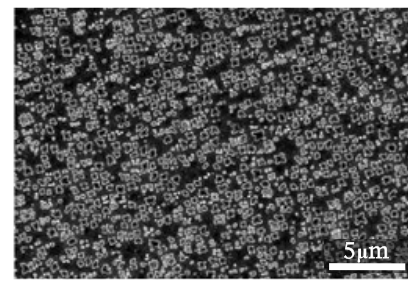

$200^{\circ} \mathrm{C} / \mathrm{h}$

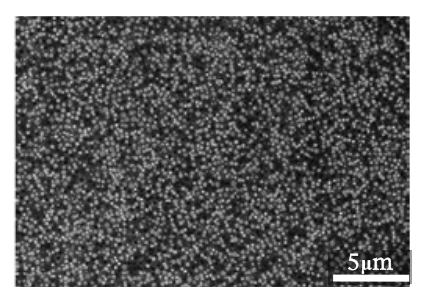

Air Cooling
Figure 4. Different $\gamma^{\prime}$ precipitates gotten by cooling treatments from $1165^{\circ} \mathrm{C} \rightarrow 1000^{\circ} \mathrm{C}$ with various cooling rates.

interface energy. On further decreasing the cooling rate, the morphology of the microstructure gradually changes to more and more irregular precipitate shapes caused by the increasing misfit strain between particle and matrix with increasing precipitate size [12].

\subsection{Improved hot deformation behaviour by $\gamma^{\prime}$ coarsening}

\subsubsection{Flow stresses}

After the cooling processes with different cooling rates, all the samples were compressed at the same deforming condition of $1130{ }^{\circ} \mathrm{C} / 0.1 \mathrm{~s}^{-1}$. It can be seen that the flow curves are quite different as illustrated in Fig. 5a. The flow stress dropping is more significantly for the specimens employed slower cooling treatments which introduced course $\gamma^{\prime}$. 

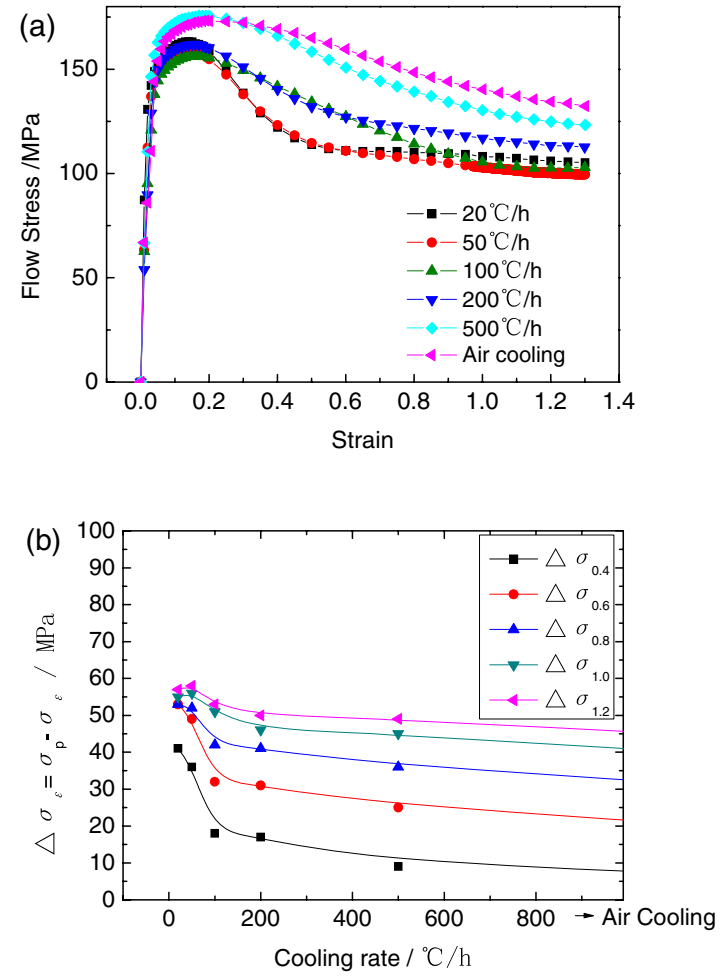

Figure 5. Effect of cooling rates on (a) flow curves and (b) $\sigma_{\varepsilon}=$ $\sigma_{p}-\sigma_{\varepsilon}$ when deformed at the condition of $1130{ }^{\circ} \mathrm{C} / 0.1 \mathrm{~s}^{-1}$.

As shown in Fig. 5b, the difference $\left(\sigma_{\varepsilon}\right)$ between peak $\operatorname{stress}\left(\sigma_{p}\right)$ and flow $\operatorname{stress}\left(\sigma_{\varepsilon}\right)$ increases with decreased cooling rate, which indicate that the softening effect during hot deformation has been enhanced by slower cooling process. Further more, smaller $\operatorname{strain}(\varepsilon)$ is needed to achieve a certain value of $\sigma$ with lower cooling rate, which means the softening rate is also increased with slower cooling process.

\subsubsection{Microstructure evolution}

Microstructure observation proves that the dynamic recrystallization softening is much easier to finish for the specimens employed slower cooling treatments. As shown in Fig. 6, the recrystallization fraction increases from about $20 \%$ to $100 \%$ after $70 \%$ deformation by slower cooling treatments at the same condition of $1130^{\circ} \mathrm{C} / 0.1 \mathrm{~s}^{-1}$.

By more detail microstructure analysis, it is believed that the promoting effect for slow cooling on recrystallization is mainly caused by $\gamma^{\prime}$ coarsening.

Generally, fine $\gamma^{\prime}$ particles block dislocations during hot deformation. The dislocation accumulates may bring more potential recrystallizing nucleation points. But because of the high dispersal level, the effective nucleation point's amount is quite limited. Meanwhile, the fine $\gamma^{\prime}$ particles strongly block the sub grain boundaries or cellular dislocations moving which will restrain the new grains forming. Therefore, fine $\gamma^{\prime}$ particles promote deformation hardening and restrain the recrystallization softening. In fact, that is the main reason for poor hot workability of the so called "Difficult-to-Deform" wrought superalloys without microstructure pre-modification.

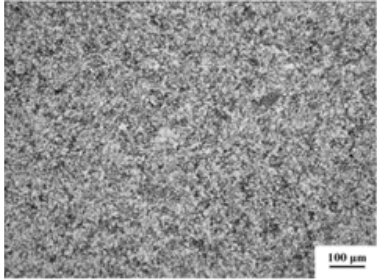

$20^{\circ} \mathrm{C} / \mathrm{h}$

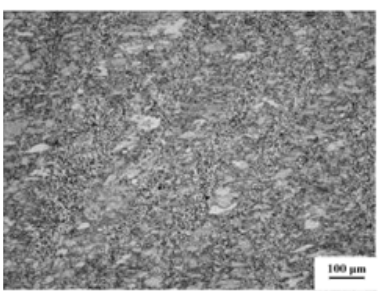

$100^{\circ} \mathrm{C} / \mathrm{h}$

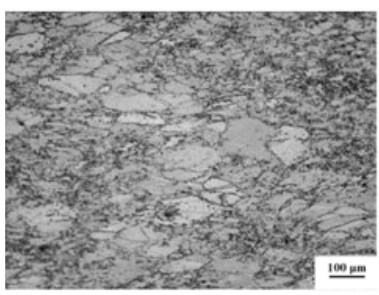

$500^{\circ} \mathrm{C} / \mathrm{h}$

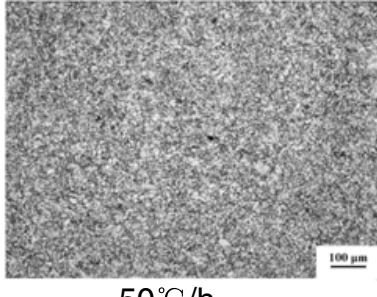

$50^{\circ} \mathrm{C} / \mathrm{h}$

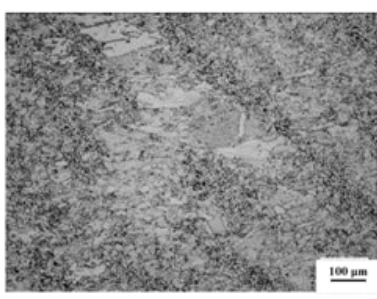

$200^{\circ} \mathrm{C} / \mathrm{h}$

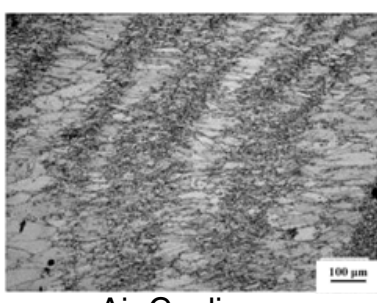

Air Cooling
Figure 6. Effect of cooling rates on recrystallization behavior when deformed at the condition of $1130^{\circ} \mathrm{C} / 0.1 \mathrm{~s}^{-1} / 70 \%$.
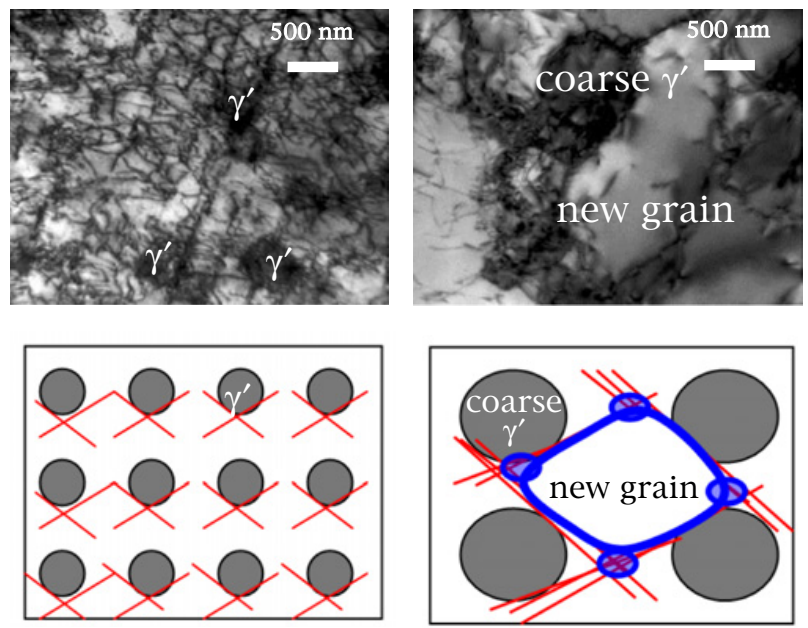

Figure 7. TEM photographs and sketch map showing effect of $\gamma^{\prime}$ coarsening on recrystallization.

As shown in the sketch map in Fig. 7, the effective nucleation point amount is increased due to the larger size of $\gamma^{\prime}$. In addition, because of the larger spacing, the blocking effect on sub-grain boundaries moving is not as strong as the fine ones. Accordingly, the recrystallization softening could be accelerated by $\gamma^{\prime}$ coarsening.

\subsubsection{Hot plasticity}

As talked above, the recrystallization softening could be accelerated by $\gamma^{\prime}$ coarsening. Meanwhile, the precipitates' hardening effect was weakened. Considering these mechanisms, it is believed that the plasticity is much 


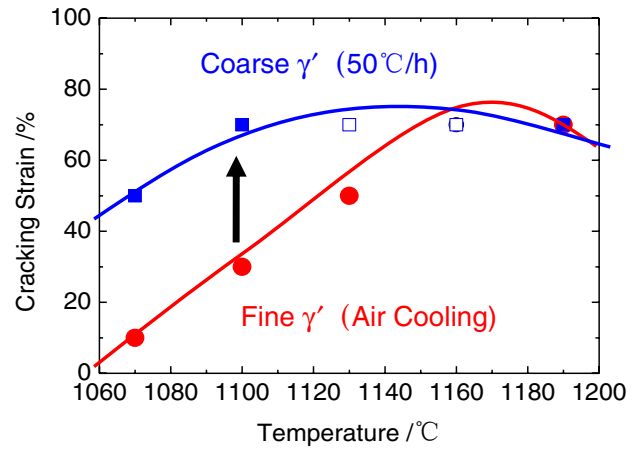

Figure 8. Effect of $\gamma^{\prime}$ coarsening on hot plasticity $\left(0.1 \mathrm{~s}^{-1}\right)$.
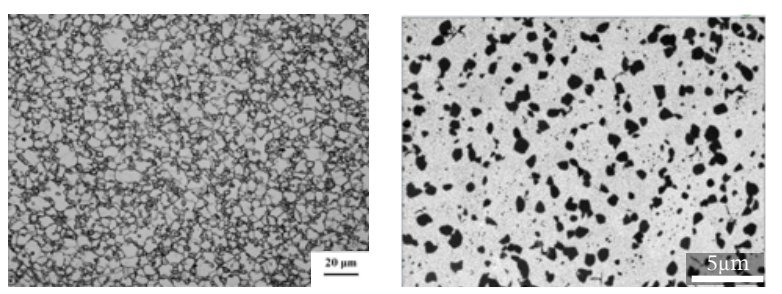

Figure 9. Modified dual-phase microstructure gotten by $\gamma^{\prime}$ coarsening and full recrystallization.

better with coarse $\gamma^{\prime}$ introduced by slow cooling treatment, which could be proved by the results in Fig. 8 .

In addition, it was reported that after cooling process with shower cooling rate like $5^{\circ} \mathrm{C} / \mathrm{h}$, fan-type $\gamma^{\prime}$ can be formed and the grain boundaries be tortured $[8,12,13]$. Existence of tortuous grain boundary can also improve the hot deformation plasticity effectively [13].

\subsection{Hot deformation behaviours of the modified dual-phase microstructures}

As mentioned in 3.2, the recrystallization softening is much easier to finish with coarsened $\gamma^{\prime}$ particles during hot deformation. So this effective pre-modification on microstructure could be used to improve the hot plasticity and break down the cast microstructures of wrought superalloys with high volume fraction of $\gamma^{\prime}$ during cogging process.

After full recrystallization by proper hot deformation, a modified dual-phase microstructure could be gotten as shown in Fig. 9, the grain size is about $5 \sim 10$ micro meters, with coarse $\gamma^{\prime}$ at grain boundaries which is $2 \sim 3$ micro meters.

As shown in Fig. 10, compared to the samples cut from the ingot with homogenised single phase microstructure (Fig. 3), the hot plasticity of the samples with modified dual-phase microstructures is much better, especially at the temperatures lower than $1160^{\circ} \mathrm{C}$ which is about the solves temperature of $\gamma^{\prime}$ phase.

Benefiting from the pinning effect by coarse $\gamma^{\prime}$ particles at grain boundaries, the microstructure doesn't change during deformation at dual-phase temperature region $\left(<1160^{\circ} \mathrm{C}\right)$ no matter what the strain is for the samples with modified dual-phase microstructure (Fig. 11). So it is unknown whether the recrystallization was happening or not by conventional microstructure observation.

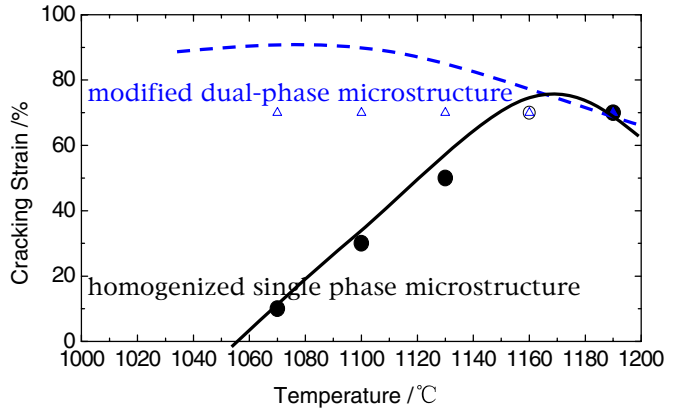

Figure 10. Hot plasticity improvement of the modified dualphase microstructure $\left(0.1 \mathrm{~s}^{-1}\right)$.

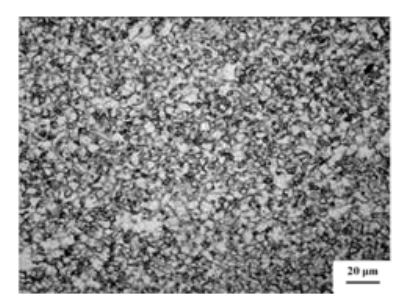

$30 \%$

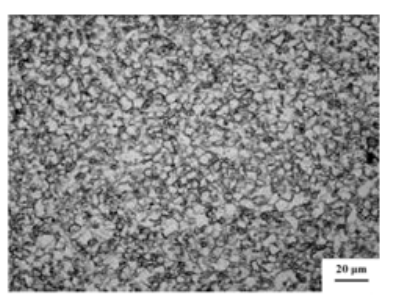

$50 \%$

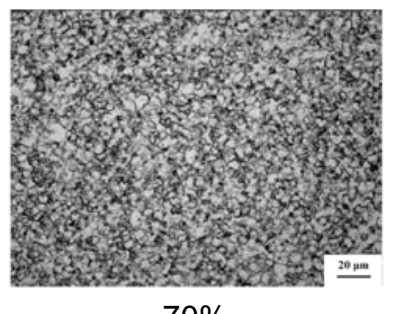

$70 \%$

Figure 11. Microstructure evolution during hot deformation of the samples with modified dual-phase microstructure $\left(1100{ }^{\circ} \mathrm{C} / 0.01 \mathrm{~s}^{-1}\right)$.

As shown in Fig. 12, the strain rate sensitive factors $(m)$ were calculated respectively for the samples with homogenized single phase microstructure and modified dual-phase microstructure. It is widely believed that the super plastic could happen if the $m$ value is larger than 0.3. So for the samples with modified dual-phase microstructure, the grain boundary sliding mechanism probably participated in during deformation at temperature lower than $1130{ }^{\circ} \mathrm{C}$ with low strain rate. It is also supposed that the coarse $\gamma^{\prime}$ particles bring in more interfaces for sliding.

More direct evidence is illustrated in Fig. 13. It should be noted that the tensile were stopped by equipment limit. The specimens were not broken during load, but fractured during cooling after unload.

\subsection{Heat insulation effect of soft lagging casing}

Compared to conventional Ni-based superalloys with low $\gamma^{\prime}$ fraction, the hot working temperature window for "Difficult-to-Deform" wrought superalloys is still limited, even though the hot workability could be improved by $\gamma^{\prime}$ coarsening. Thereby, effective heat insulation measures are still important for hot working practice, especially for the cogging operation to break down the cast microstructures. 

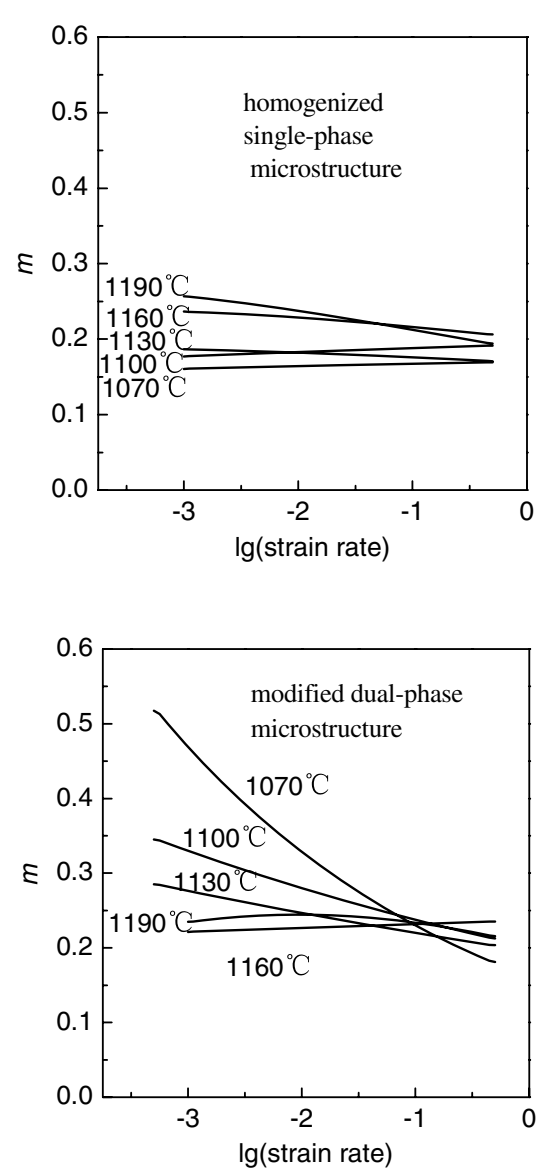

Figure 12. The strain rate sensitive factors of the samples with single phase and modified dual-phase microstructure.

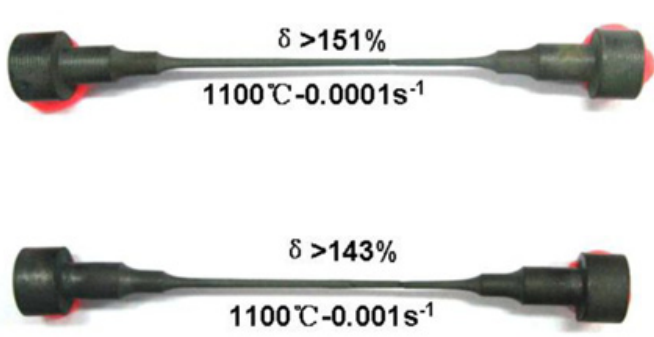

Figure 13. Super-plasticity phenomenon of modified dual-phase microstructure.

Normally, the cast ingots can soak a desirable temperature by pre-heating. Accordingly, a soft lagging casing method using fiber heat-insulator and glass binder was proposed to retard the heat radiation of the pre-heated ingots during the cogging operation.

It is demonstrated in Fig. 14 that the surface temperature of a $340 \mathrm{~mm}$ diameter and $460 \mathrm{~mm}$ long ingot dropped from pre-heated $1170^{\circ} \mathrm{C}$ to $800{ }^{\circ} \mathrm{C}$ after 1000 seconds exposure but can be kept over $1050^{\circ} \mathrm{C}$ when covering the soft lagging layer (measured by thermocouple). This kind of "soft" cladding technique is much more convenient than the "hard" canning method using steel sheet or piping.
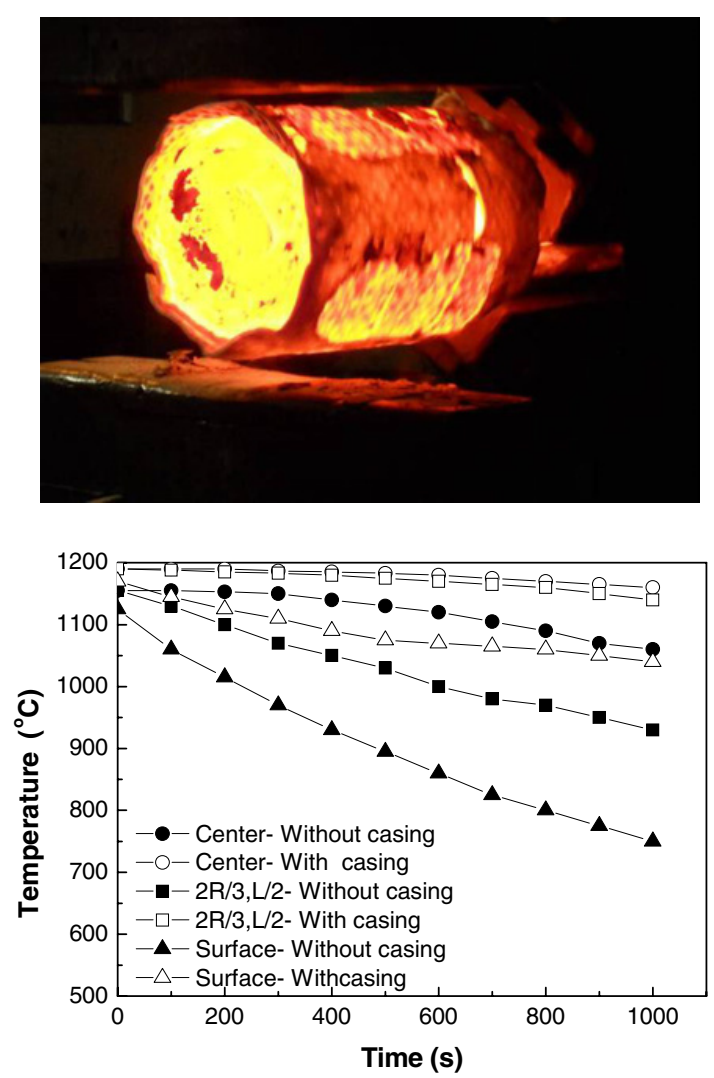

Figure 14. Effect of soft lagging casing during cogging.

\section{Conclusions}

1 Slowing down the cooling rate influence $\gamma^{\prime}$ precipitation obviously for wrought superalloys with high volume fraction of $\gamma^{\prime}$;

2 Cooling process with low cooling rates can produce coarse $\gamma^{\prime}$ before deformation. $\gamma^{\prime}$ coarsening could significantly change plastic flow behavior that helps to break down the cast microstructures and improve hot plasticity of wrought superalloys with high volume fraction of $\gamma^{\prime}$.

3 After full recrystallization, a modified dual-phase microstructure containing refined $\gamma$ matrix plus coarse $\gamma^{\prime}$ shows super-plasticity during subsequent hot deformation.

4 It proved that soft lagging casing method is effective to retard the surface heat radiation of the pre-heated ingots during cogging operation.

\section{References}

[1] R. C. Reed, The Superalloys Fundamentals and Applications (Cambridge University Press, Cambridge, 2009)

[2] D. Furrer, H. Fecht, JOM. 51, 14 (1999)

[3] R. S. Moshatghin, S. Asgari, J. Alloys Compd. 368, 144 (2004)

[4] P. M. Sarosi, B. Wang, J. P. Simons, Y. Wang, M. J. Mills, Scripta Mater. 57, 767 (2007)

[5] J. Zrnik, P. Strunz, V. Vrchovinsky, O.Muransky, Z. Novy, A.Wiedenmann, Mater. Sci. Eng. A 387-389, 728 (2004) 
[6] H. Monajati, M. Jahazi, R. Bahrami, S. Yue, Mater. Sci. Eng. A 373, 286 (2004)

[7] R. J. Mitchell, M. C. Hardy, M. Preuss, S. Tin, Superalloys 2004, 361 (TMS Press, Champion, 2004)

[8] X. D Lv, J. H. Du, Q. Deng, Z. Y. Zhong, J. Alloy. Compd. 477, 103 (2009)

[9] Z. N. Bi, J. L. Qu, J. H. Du, Proc. Eng. 27, 923 (2012)
[10] F. E. Sczerzenie, G.E. Maurer, Superalloys 1984, 573 (TMS Press, Champion, 1984)

[11] D. J. BryantG. Mcintosh, Superalloys 1996, 713 (TMS Press, Champion, 1996)

[12] R. RadisM. Schaffer, G. Kothleitner, P. Polt, E. Kozeschnik, Superalloys 1996, 829 (TMS Press, Champion, 2008)

[13] X. D Lv, J. H. Du, Q. Deng, Z. Y. Zhong, J. Alloy. Compd. 486, 195 (2009) 